\title{
Robust Nonlinear Model Predictive Control of a Run-of-Mine Ore Milling Circuit
}

\author{
Loutjie C. Coetzee, Ian K. Craig, and Eric C. Kerrigan
}

\begin{abstract}
This brief investigates the feasibility of applying a robust nonlinear model predictive controller to a run-of-mine ore milling circuit, and the conditions under which such a controller might be worthwhile implementing. The run-of-mine ore milling circuit model used consists of nonlinear modules for the individual components of the milling circuit, allowing for arbitrary milling circuit configurations to be modeled. The model is cast into a robust nonlinear model predictive control framework, and a practically motivated simulation of the mill model being controlled by an robust nonlinear model predictive control (RNMPC) controller is presented. Issues related to implementing such a controller are investigated.
\end{abstract}

Index Terms-Grinding mill, milling circuit, process control, robust nonlinear model predictive control (RNMPC), run-of-mine (ROM) ore.

\section{INTRODUCTION}

$\mathbf{T}$ HE run-of-mine (ROM) ore milling circuit plays an important role in processing mined ore. This forms part of the comminution process of liberating the desired metals or minerals from the ore. At the heart of the milling circuit is usually a ball, rod, semi-autogenous (SAG), or autogenous (AG) mill. AG mills use only the feed ore as grinding medium, while SAG and ball mills use steel balls together with the feed ore as grinding medium. The difference between SAG and ball mills is the fraction of the total charge consisting of balls and that SAG mills process ROM ores, while the feed to the rod and ball mills is first crushed. Rod mills use long steel rods together with the feed ore as grinding medium.

The milling process is complicated by significant input and plant uncertainties, because the feed ore forms part of the grinding medium and the variation in feed ore contributes to the input uncertainty. The feed ore distribution in terms of hardness and size affects the breakage kinetics and contributes to the plant uncertainties. Proper design of the milling circuit alone cannot eliminate the disturbances. Feedback control systems play an important part in reducing the effects of disturbances and increasing efficiency [1].

\footnotetext{
Manuscript received March 04, 2008; revised November 26, 2008. Manuscript received in final form January 16, 2009. First published March 27, 2009; current version published December 23, 2009. Recommended by Associate Editor S. L. Jásmá-Jounela. This work was sponsored in part by the National Research Foundation of South Africa, by Mintek, and by the University of Pretoria.

L. Coetzee and I. Craig are with the Department of Electrical, Electronic, and Computer Engineering, University of Pretoria, Pretoria 0002, South Africa (e-mail: loutjie.coetzee@up.ac.za; icraig@ postino.up.ac.za).

E. Kerrigan is with the Department of Aeronautics and Department of Electrical and Electronic Engineering, Imperial College London, London SW7 2AZ, U.K. (e-mail: e.kerrigan@imperial.ac.uk).

Color versions of one or more of the figures in this brief are available online at http://ieeexplore.ieee.org.

Digital Object Identifier 10.1109/TCST.2009.2014641
}

In milling circuits it is difficult to control important variables such as the product particle size, because independent control of the amount, size and hardness of the grinding medium in the mill is not possible. This causes significant uncontrollable disturbances and uncertain plant dynamics [1].

Advanced control has not been readily adopted by the mineral processing industry [2], although various applications of MPC to grinding mill circuits have been reported in the literature (see, e.g., [3]). As far as the authors are aware, the application of robust nonlinear model predictive control (RNMPC) to a ROM ore milling circuit described in this brief, has not been reported on before in the open literature.

Milling circuits have many different configurations. A reduced complexity nonlinear model similar to those found in literature [4] is used for RNMPC. The nonlinear model consists of nonlinear modules for the mill, sump, and cyclone. Being able to use the nonlinear components and arrange them in different configurations is advantageous when simulating different milling configurations.

Applying robust nonlinear control, such as RNMPC, further simplifies the process by eliminating the need for different simulation and control models. The nonlinear nature and the uncertainties are explicitly incorporated in the controller to provide the best performance and stability tradeoff. Robust control aims to guarantee stability and improved performance when uncertainty and disturbances are present. This is accomplished by incorporating an explicit description of the uncertainties and disturbances into the prediction model of the controller. The controller then usually calculates the optimal control sequence or feedback laws that optimize a given objective function for the worst-case realization of the system as defined by the worst-case objective function.

There are a number of ways to approach RNMPC. Some authors, such as [5], use Lyapunov stability theory to formulate the RNMPC that also defines the set of initial conditions that will satisfy the stability conditions. This ensures that the controller is feasible for the initial state and as a result remains feasible for all future states under control.

Closed-loop min-max RNMPC [6] takes the effect of feedback into consideration when predicting the future state trajectories subject to uncertainty and disturbances, which reduces the spread in predicted future state trajectories compared to openloop formulations. This reduced spread in trajectories, increases the feasible region of the controller and reduces the conservatism of the controller.

This brief is organized as follows. Section II describes a comprehensive modularized ROM ore milling circuit model that can be used for controller design and simulation. The ROM ore milling circuit model is then cast into an RNMPC framework that is described in Section III. Section IV describes practically 


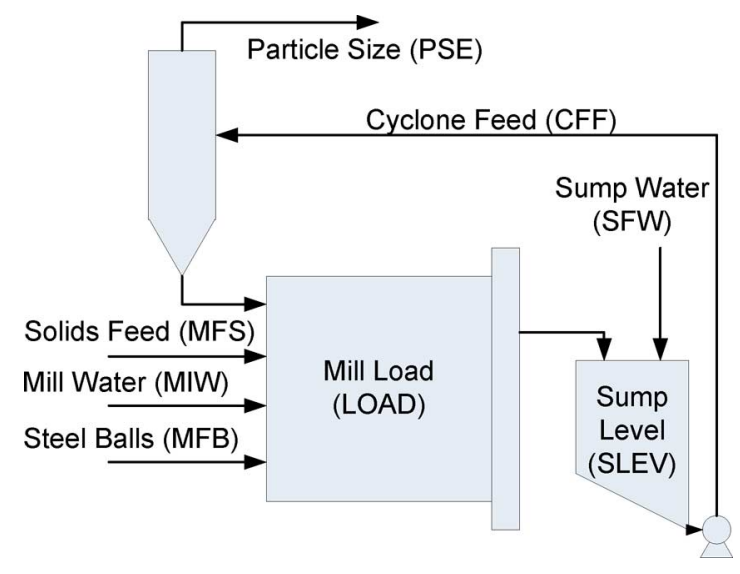

Fig. 1. ROM ore milling circuit.

motivated simulation results of the mill model being controlled by a RNMPC controller. Some implementation issues are discussed in Section V and conclusions are drawn in Section VI.

\section{MiLl Modelling}

The circuit is fed gold-bearing ore at about 100 tons/hour and grinds it down to a product with a particle size of $80 \%$ smaller than $75 \mu \mathrm{m}\left(P_{80}=75 \mu \mathrm{m}\right)$. The ROM mill is operated in closed circuit with a hydrocyclone that separates the fine material (product) from the coarse material (out-of-specification material), which is recycled to the mill. The gold is then extracted through a leaching process downstream.

A typical mill has dimensions of $5 \mathrm{~m}$ in diameter and a length of $9 \mathrm{~m}$. The mill is supported by pressurized-oil circumferential bearings. The mill features lifter bars and solid white-iron liners and it is operated at $90 \%$ of critical speed [7]. The mill discharges slurry through an end-discharge grate into a sump. The slurry is diluted with water in the sump and pumped to the hydrocyclone for classification. The hydrocyclone has an internal diameter of $1 \mathrm{~m}$. The underflow of the cyclone, water, and feed ore constitute the mill feed.

The variables of the mill (see Fig. 1) that are typically controlled are the product particle-size (PSE), the fraction of mill volume filled with material (LOAD), and the volume of slurry in the sump (SLEV). The inputs to the mill that are typically manipulated automatically are the flow-rate of water to the sump (SFW), the flow-rate of slurry to the cyclone (CFF), the feed-rate of solids to the mill (MFS), the flow-rate of water to the mill inlet (MIW), and feed-rate of steel balls to the mill (MFB). Steel balls, which are usually added to the mill feed by the operator in discrete quantities, will for this study be treated as a continuous variable.

\section{A. Objectives in Mill Control}

The control of the milling circuit has multiple objectives, first, to stabilize the system, and second, to optimize the economics of the process [8]. The economic objective is divided into sub-objectives that each contributes to the overall economic objective of the milling process. A set of possible sub-objectives for the milling circuit are to [1]:

1) improve product quality

a) by maintaining the required grind fineness;

b) decreasing the fluctuations in product size;
TABLE I

MODEL NOMENCLATURE

\begin{tabular}{|c|c|}
\hline Symbol & Description \\
\hline Volumetric flow-rates & used for internal flows: in $(i)$, out $(o)$, underflow $(u)$ \\
\hline$V_{\text {wi }}, V_{\text {wo }}, V_{\text {wu }}$ & Water $\left[\mathrm{m}^{3} /\right.$ hour $]$ \\
\hline$V_{\mathrm{si}}, V_{\mathrm{so}}, V_{\mathrm{su}}$ & Solids $\left[\mathrm{m}^{3} /\right.$ hour $]$ \\
\hline$V_{\mathrm{ci}}, V_{\mathrm{co}}, V_{\mathrm{cu}}$ & Coarse $\left(V_{\mathrm{s}}-V_{\mathrm{f}}\right)\left[\mathrm{m}^{3} /\right.$ hour $]$ \\
\hline$V_{\mathrm{fi}}, V_{\mathrm{fo}}, V_{\mathrm{fu}}$ & Fines $\left[\mathrm{m}^{3} /\right.$ hour $]$ \\
\hline$V_{\mathrm{ri}}, V_{\mathrm{ro}}$ & Rocks $\left[\mathrm{m}^{3} /\right.$ hour $]$ \\
\hline$V_{\mathrm{bi}}, V_{\mathrm{bo}}$ & Balls $\left[\mathrm{m}^{3} /\right.$ hour$]$ \\
\hline$D_{s}, D_{b}$ & $\begin{array}{l}\text { Density of feed ore }\left(D_{s}\right) \text { and steel balls }\left(D_{b}\right) \\
{\left[\mathrm{kg} / \mathrm{m}^{3}\right]}\end{array}$ \\
\hline
\end{tabular}

2) maximize throughput;

3) minimize the amount of steel that is consumed for each ton of fines produced;

4) to minimize the power consumed for each ton of fines produced, etc.

The objectives above are interrelated and require tradeoffs to be made. The main trade-offs are between particle size of the product and the throughput of solids (objectives 1a and 2) as well as power consumption and throughput (objectives 2 and 4).

\section{B. Mill Circuit Model Modules}

The model consists of separate modules for the feeder, mill, sump, and hydrocyclone. These modules can be connected in various configurations depending on the plant setup. The model uses five states, namely water, rocks, solids, fines, and steel balls. Rocks are defined as the ore that is too big to be discharged from the mill. Solids are defined as the coarse ore as well as the fines. Coarse ore is defined as the ore that is discharged from the mill, but is out-of-specification, thus larger than $75 \mu \mathrm{m}$. Fines are defined as the ore that is in-specification and thus smaller than $75 \mu \mathrm{m}$.

The nomenclature for the model is shown in Tables I-III.

1) Feeder Module: The feeder module is a very simple module that takes the feed-rate of ore and divides it into the ore streams (fines, coarse, and rock) that will be used throughout the model. This module can be replaced by models of real feeders, for example vibratory feeders.

The flow-rate of the various constituents of the feed from the feeder are defined as

$$
\begin{aligned}
& V_{\text {wo }} \triangleq \text { MIW } \\
& V_{\text {so }} \triangleq \frac{\text { MFS }}{D_{s}}\left(1-\alpha_{r}\right) \\
& V_{\text {fo }} \triangleq \alpha_{f} \cdot \frac{\text { MFS }}{D_{s}} \\
& V_{\text {ro }} \triangleq \alpha_{r} \cdot \frac{\text { MFS }}{D_{s}} \\
& V_{\text {bo }} \triangleq \frac{\text { MFB }}{D_{b}} .
\end{aligned}
$$

2) Mill Module: The mill module is capable of modelling various mill types such as rod, ball, SAG, and AG mills. It is similar to the models found in the literature, but adds the effect of mill power and slurry rheology [9] to the breakage and power functions. 
TABLE II

CONSTRAINTS AND OPERATING POINT

\begin{tabular}{|c|c|c|c|c|c|}
\hline Variable & Min & Max & $\mathrm{OP}$ & W & Description \\
\hline$X_{\mathrm{mw}}$ & 0 & 50 & 8.53 & - & $\begin{array}{l}\text { The holdup of water in } \\
\text { the mill. }\left[\mathrm{m}^{3}\right]\end{array}$ \\
\hline$X_{\mathrm{ms}}$ & 0 & 50 & 9.47 & - & $\begin{array}{l}\text { The holdup of ore in the } \\
\text { mill. }\left[\mathrm{m}^{3}\right]\end{array}$ \\
\hline$X_{\mathrm{mf}}$ & 0 & 50 & 3.54 & - & $\begin{array}{l}\text { The holdup of fine ore in } \\
\text { the mill. }\left[\mathrm{m}^{3}\right]\end{array}$ \\
\hline$X_{\mathrm{mr}}$ & 0 & 50 & 20.25 & - & $\begin{array}{l}\text { The holdup of rock in the } \\
\text { mill. }\left[\mathrm{m}^{3}\right]\end{array}$ \\
\hline$X_{\mathrm{mb}}$ & 0 & 20 & 6.75 & - & $\begin{array}{l}\text { The holdup of balls in the } \\
\text { mill. }\left[\mathrm{m}^{3}\right]\end{array}$ \\
\hline$X_{\mathrm{sw}}$ & 0 & 10 & 3.95 & - & $\begin{array}{l}\text { The holdup of water in } \\
\text { the sump. }\left[\mathrm{m}^{3}\right]\end{array}$ \\
\hline$X_{\mathrm{ss}}$ & 0 & 10 & 1.05 & - & $\begin{array}{l}\text { The holdup of ore in the } \\
\text { sump. }\left[\mathrm{m}^{3}\right]\end{array}$ \\
\hline$X_{\mathrm{sf}}$ & 0 & 10 & 0.14 & - & $\begin{array}{l}\text { The holdup of fine ore in } \\
\text { the sump. }\left[\mathrm{m}^{3}\right]\end{array}$ \\
\hline MIW & 0 & 100 & 33.33 & 0.01 & $\begin{array}{l}\text { The flow-rate of water to } \\
\text { the circuit. }\left[\mathrm{m}^{3} / \text { hour] }\right.\end{array}$ \\
\hline MFS & 0 & 200 & 100 & 0.01 & $\begin{array}{l}\text { The flow-rate of ore to the } \\
\text { circuit (consists of rocks, } \\
\text { coarse and fine ore). } \\
\text { [tons/hour] }\end{array}$ \\
\hline MFB & 0 & 4 & 2 & 0.01 & $\begin{array}{l}\text { The flow-rate of balls to } \\
\text { the circuit. [tons/hour] }\end{array}$ \\
\hline$\alpha_{\text {speed }}$ & 0.7 & 1.0 & 0.82 & - & $\begin{array}{l}\text { The fraction of critical } \\
\text { mill speed. }\end{array}$ \\
\hline $\mathrm{CFF}$ & 400 & 500 & 443 & 0.01 & $\begin{array}{l}\text { The flow-rate of water } \\
\text { from the sump to the } \\
\text { cyclone. }\left[\mathrm{m}^{3} / \text { hour] }\right.\end{array}$ \\
\hline SFW & 0 & 400 & 267 & 0.01 & $\begin{array}{l}\text { The flow-rate of extra } \\
\text { water to the sump. } \\
{\left[\mathrm{m}^{3} / \text { hour }\right]}\end{array}$ \\
\hline PSE & 60 & 90 & 80 & 100 & $\begin{array}{l}\text { Product particle-size. [\% } \\
<75 \mu \mathrm{m}]\end{array}$ \\
\hline LOAD & 30 & 50 & 45 & 100 & $\begin{array}{l}\text { The total charge of the } \\
\text { mill. [\%] }\end{array}$ \\
\hline SLEV & 2 & 9.5 & 5.0 & - & $\begin{array}{l}\text { The level of the sump. } \\
{\left[\mathrm{m}^{3}\right]}\end{array}$ \\
\hline$\varphi$ & 0 & 1 & 0.51 & 0 & $\begin{array}{l}\text { Rheology Factor. } \\
\text { Product throughput }\end{array}$ \\
\hline THROUGHPUT & 100 & 0 & 200 & 1 & $\begin{array}{l}\text { consisting of coarse and } \\
\text { fine solids. [tons/hour] }\end{array}$ \\
\hline$P_{\text {mill }}$ & 0 & 2000 & 2000 & 0 & $\begin{array}{l}\text { Power draw of the mill } \\
\text { motor. }[\mathrm{kW}]\end{array}$ \\
\hline
\end{tabular}

It receives the ore, balls, and water and incorporates models that describe the production of fines, consumption of rock, ball wear, and various discharge mechanisms, e.g., grate discharge. The rheology factor which relates to the fluidity of the slurry inside the mill [9] is defined as

$$
\varphi \triangleq\left\{\frac{\max \left[0,\left(X_{\mathrm{mw}}-\left(\left(\frac{1}{\varepsilon_{w s}}\right)-1\right) X_{\mathrm{ms}}\right)\right]}{X_{\mathrm{mw}}}\right\}^{0.5}
$$

and the mill power is defined as

$$
\begin{aligned}
& P_{\text {mill }} \triangleq P_{\max } \cdot\left\{1-\delta_{P v} Z_{x}^{2}\right. \\
& \left.\quad-2 \cdot \chi_{P} \cdot \delta_{P v} \cdot \delta_{P s} \cdot Z_{x} \cdot Z_{r}-\delta_{P s} \cdot Z_{r}^{2}\right\} \cdot\left(\alpha_{\text {speed }}\right)^{\alpha_{P}}
\end{aligned}
$$

where the effect of the load on the power consumption is defined as $Z_{x} \triangleq\left(X_{\mathrm{mb}}+X_{\mathrm{mr}}+X_{\mathrm{ms}}+X_{\mathrm{mw}}\right) /\left(v_{P_{\max }} \cdot v_{\text {mill }}-1\right)$ and the effect of rheology on power consumption is defined as $Z_{r} \triangleq\left(\varphi / \varphi_{P_{\max }}\right)-1$. The production of fines is a linear function of the total mill volume filling $\left(\mathrm{LOAD} \triangleq\left(X_{\mathrm{mw}}+X_{\mathrm{ms}}+X_{\mathrm{mr}}+X_{\mathrm{mb}}\right)\right)$. The production of
TABLE III

\begin{tabular}{|c|c|c|c|c|c|}
\hline Parm & Nom & Min & Max & $\% \Delta$ & Description \\
\hline$\alpha_{f}$ & 0.1 & 0.05 & 0.15 & 50 & $\begin{array}{l}\text { Fraction of fines in the } \\
\text { ore. [dimensionless] }\end{array}$ \\
\hline$\alpha_{r}$ & 0.1 & 0.05 & 0.15 & 50 & $\begin{array}{l}\text { Fraction of rock in the } \\
\text { ore. [dimensionless] }\end{array}$ \\
\hline$\phi_{f}$ & 28 & 14 & 42 & 50 & $\begin{array}{l}\text { Power needed for a ton of } \\
\text { fines produced. }[\mathrm{kW} \cdot \mathrm{hr} / \mathrm{ton}]\end{array}$ \\
\hline$\phi_{r}$ & 69 & 55 & 83 & 20 & $\begin{array}{l}\text { Rock abrasion factor. } \\
{[\mathrm{kW} \cdot \mathrm{hr} / \mathrm{ton}]}\end{array}$ \\
\hline$\phi_{b}$ & 94 & 89 & 99 & 5 & $\begin{array}{l}\text { Steel abrasion factor. } \\
{[\mathrm{kW} \cdot \mathrm{hr} / \mathrm{ton}]}\end{array}$ \\
\hline$\varepsilon_{w s}$ & 0.6 & - & 一 & - & $\begin{array}{l}\text { Maximum water-to-solids } \\
\text { volumetric ratio at zero } \\
\text { pulp flow. [dimensionless] }\end{array}$ \\
\hline$V_{V}$ & 40 & - & - & - & $\begin{array}{l}\text { Volumetric flow per } \\
\text { "flowing volume" driving } \\
\text { force. }\left[\mathrm{hr}^{-1}\right]\end{array}$ \\
\hline$P_{\max }$ & 2000 & - & - & - & $\begin{array}{l}\text { Maximum mill motor } \\
\text { power. }[\mathrm{kW}]\end{array}$ \\
\hline$\delta_{P v}$ & 1 & - & - & - & $\begin{array}{l}\text { Power-change parameter } \\
\text { for volume. } \\
\text { [dimensionless] }\end{array}$ \\
\hline$v_{P_{\max }}$ & 0.45 & - & - & - & $\begin{array}{l}\text { Fraction of mill volume } \\
\text { filled for maximum power. } \\
\text { [dimensionless] }\end{array}$ \\
\hline$\delta_{P s}$ & 1 & — & - & - & $\begin{array}{l}\text { Power-change parameter } \\
\text { for fraction solids. } \\
\text { [dimensionless] }\end{array}$ \\
\hline$\varphi_{P_{\max }}$ & 0.51 & - & - & - & $\begin{array}{l}\text { Rheology factor for } \\
\text { maximum mill power. } \\
\text { [dimensionless] }\end{array}$ \\
\hline$\alpha_{P}$ & 0.82 & - & - & - & $\begin{array}{l}\text { Fractional power reduction } \\
\text { per fractional reduction } \\
\text { from maximum mill } \\
\text { speed. [dimensionless] }\end{array}$ \\
\hline$v_{\text {mill }}$ & 100 & - & - & - & Mill volume. $\left[\mathrm{m}^{3}\right]$ \\
\hline$\alpha_{\phi_{f}}$ & 0.01 & - & - & - & $\begin{array}{l}\text { Fractional change in } \\
\mathrm{kW} / \text { fines produced per } \\
\text { change in fractional filling } \\
\text { of mill. [dimensionless] }\end{array}$ \\
\hline$\chi_{P}$ & 0 & - & - & - & $\begin{array}{l}\text { Cross-term for maximum } \\
\text { power. [dimensionless] }\end{array}$ \\
\hline$\varepsilon_{c}$ & 184 & 175 & 193 & 5 & $\begin{array}{l}\text { Coarse split } \\
. \text { [dimensionless] }\end{array}$ \\
\hline$\alpha_{s u}$ & 0.16 & 0.15 & 0.17 & 5 & $\begin{array}{l}\text { Fraction solids in } \\
\text { underflow. [dimensionless] }\end{array}$ \\
\hline$C_{1}$ & 0.6 & - & - & - & Constant. [dimensionless] \\
\hline$C_{3}$ & 0.7 & - & - & - & Constant. [dimensionless] \\
\hline$C_{4}$ & 3 & - & - & - & Constant. [dimensionless] \\
\hline$C_{5}$ & 3 & - & - & - & Constant [dimensionless] \\
\hline
\end{tabular}

Nominal, Minimum AND MAXIMUM PARAMETER VALUES FOR A Closed-CIRCUIT ROM MILLING CIRCUIT

fines is defined as

$$
\mathrm{FP} \triangleq \frac{P_{\text {mill }}}{D_{s} \cdot\left\{\phi_{f} \cdot\left[1+\alpha_{\phi_{f}} \cdot\left(\frac{\mathrm{LOAD}}{v_{\text {mill }}}-v_{P_{\max }}\right)\right]\right\}} .
$$

The fines produced from rocks are not distinguished from fines produced from the coarse ore.

The rocks in the mill grind down to coarse and/or fines in indeterminable ratios. The total fines produced are modelled to come from both rocks and coarse material. The yield of coarse and fines from rocks will therefore not be modelled, only the consumption of rocks. The consumption is at it highest with high power, fluid slurry and relatively low amounts of fine and coarse ore. Rock consumption is defined as

$$
\mathrm{RC} \triangleq\left(\frac{1}{D_{s} \cdot \phi_{r}}\right) \cdot P_{\mathrm{mill}} \cdot \varphi\left(\frac{X_{\mathrm{mr}}}{X_{\mathrm{mr}}+X_{\mathrm{ms}}}\right) .
$$


The steel balls inside the mill grind away over time. The consumption of the steel balls are at its highest with high power, fluid slurry and high ball loadings. Ball consumption is defined as

$$
\mathrm{BC} \triangleq\left(\frac{1}{D_{b} \cdot \phi_{b}}\right) \cdot P_{\mathrm{mill}} \cdot \varphi \cdot\left(\frac{X_{\mathrm{mb}}}{X_{\mathrm{mb}}+X_{\mathrm{mr}}+X_{\mathrm{ms}}}\right) .
$$

The discharge flow-rates of the various constituents of the mill charge are defined as

$$
\begin{aligned}
& V_{\mathrm{to}} \triangleq V_{V} \cdot \varphi \cdot X_{\mathrm{mw}} \\
& V_{\mathrm{wo}} \triangleq V_{\mathrm{to}} \cdot\left(\frac{X_{\mathrm{mw}}}{X_{\mathrm{ms}}+X_{\mathrm{mw}}}\right) \\
& V_{\mathrm{so}} \triangleq V_{\mathrm{to}} \cdot\left(\frac{X_{\mathrm{ms}}}{X_{\mathrm{ms}}+X_{\mathrm{mw}}}\right) \\
& V_{\mathrm{fo}} \triangleq V_{\mathrm{to}} \cdot\left(\frac{X_{\mathrm{mf}}}{X_{\mathrm{mr}}+X_{\mathrm{mw}}}\right)
\end{aligned}
$$

where $V_{\text {bo }} \triangleq 0$ and $V_{\text {ro }} \triangleq 0$ because it is assumed that the rocks and balls cannot escape through the discharge grate. The changes in holdups of the various constituents of the mill charge are defined as

$$
\begin{aligned}
& \frac{d X_{\mathrm{mw}}}{d t} \triangleq V_{\mathrm{wi}}-V_{\mathrm{wo}} \\
& \frac{\partial X_{\mathrm{ms}}}{\partial t} \triangleq V_{\mathrm{si}}-V_{\mathrm{so}}+\mathrm{RC} \\
& \frac{\partial X_{\mathrm{mf}}}{\partial t} \triangleq V_{\mathrm{fi}}-V_{\mathrm{fo}}+\mathrm{FP} \\
& \frac{\partial X_{\mathrm{mr}}}{\partial t} \triangleq V_{\mathrm{ri}}-\mathrm{RC} \\
& \frac{\partial X_{\mathrm{mb}}}{\partial t} \triangleq V_{\mathrm{bi}}-\mathrm{BC} .
\end{aligned}
$$

3) Mixed-Sump Module: The mixed-sump module assumes that the water, fines and coarse material are fully mixed. The sump only handles water, fine, and coarse ore because it is assumed that the rock and the balls remain in the mill. The discharge flow-rates of the various constituents of the slurry inside the sump are defined as

$$
\begin{gathered}
V_{\mathrm{wo}} \triangleq \mathrm{CFF} \cdot\left(\frac{X_{\mathrm{sw}}}{X_{\mathrm{ss}}+X_{\mathrm{sw}}}\right) \\
V_{\mathrm{so}} \triangleq \mathrm{CFF} \cdot\left(\frac{X_{\mathrm{ss}}}{X_{\mathrm{ss}}+X_{\mathrm{sw}}}\right) \\
V_{\mathrm{fo}} \triangleq \mathrm{CFF} \cdot\left(\frac{X_{\mathrm{sf}}}{X_{\mathrm{ss}}+X_{\mathrm{sw}}}\right) .
\end{gathered}
$$

The changes in holdups of the various constituents of the slurry inside the sump are defined as

$$
\begin{aligned}
& \frac{\partial X_{\mathrm{sw}}}{\partial t} \triangleq V_{\mathrm{wi}}+\mathrm{SFW}-V_{\mathrm{wo}} \\
& \frac{\partial X_{\mathrm{ss}}}{\partial t} \triangleq V_{\mathrm{si}}-V_{\mathrm{so}} \\
& \frac{\partial X_{\mathrm{sf}}}{\partial t} \triangleq V_{\mathrm{fi}}-V_{\mathrm{fo}} .
\end{aligned}
$$

The sump level is defined as $\mathrm{SLEV} \triangleq X_{\mathrm{sw}}+X_{\mathrm{ss}}$. The cyclone feed density is defined as CFD $\triangleq$ $X_{\mathrm{sw}}+D_{\mathrm{s}} \cdot X_{\mathrm{ss}} /\left(X_{\mathrm{sw}}+X_{\mathrm{ss}}\right)$.

4) Hydrocyclone Module: The hydrocyclone is a classification device that splits a slurry feed with regard to weight, which usually relate to the size of the particles. Lighter particles are forced out at the overflow of the cyclone, while the heavier particles get forced out at the underflow. The cyclone model is designed to model the product size and density accurately by taking the effects of angular velocity of the particle inside the cyclone, slurry density, and viscosity into account. The model is based on the empirical hydrocyclone models of Plitt and Nageswararao [10]. The flow-rates of the various constituents of the slurry at the underflow of the hydrocyclone are defined as

$$
\begin{aligned}
V_{\mathrm{cu}} \triangleq & V_{\mathrm{ci}} \cdot\left(1-C_{1} \cdot e^{\left(-V_{t i} / \varepsilon_{c}\right)}\right) \\
& \cdot\left(1-\left(\frac{F_{i}}{C_{3}}\right)^{C_{4}}\right) \cdot\left(1-P_{i}^{C_{5}}\right) \\
F_{u} \triangleq & 0.6-\left(0.6-F_{i}\right) \cdot e^{\left(-V_{\mathrm{cu}} / \alpha_{s u} \varepsilon_{c}\right)} \\
V_{\mathrm{wu}} \triangleq & V_{\mathrm{wi}} \cdot \frac{\left(V_{\mathrm{cu}}-F_{u} \cdot V_{\mathrm{cu}}\right)}{\left(F_{u} \cdot V_{\mathrm{wi}}+F_{u} \cdot V_{\mathrm{fi}}-V_{\mathrm{fi}}\right)} \\
V_{\mathrm{fu}} \triangleq & V_{\mathrm{fi}} \cdot \frac{\left(V_{\mathrm{cu}}-F_{u} \cdot V_{\mathrm{cu}}\right)}{\left(F_{u} \cdot V_{\mathrm{wi}}+F_{u} \cdot V_{\mathrm{fi}}-V_{\mathrm{fi}}\right)}
\end{aligned}
$$

where $F_{i} \triangleq V_{\mathrm{si}} /\left(V_{\mathrm{wi}}+V_{\mathrm{si}}\right)$ and $P_{i} \triangleq V_{\mathrm{fi}} / V_{\mathrm{si}}$. The product particle size is defined as PSE $\triangleq V_{\mathrm{fo}} /\left(V_{\mathrm{co}}+V_{\mathrm{fo}}\right)$, where $V_{\mathrm{fo}} \triangleq$ $V_{\mathrm{fi}}-V_{\mathrm{fu}}$ and $V_{\mathrm{co}} \triangleq V_{\mathrm{ci}}-V_{\mathrm{cu}}$. The product throughput is defined as THROUGHPUT $\triangleq V_{\text {co }}+V_{\text {fo }}$.

\section{Robust Nonlinear Model Predictive Control}

NMPC utilizes a nonlinear model to predict the behavior of the plant and calculate the optimal control moves or control laws with regard to a specified objective function. NMPC is derived from nonlinear optimal control over a constant or varying time interval into the future $\left[t_{k}, t_{k}+T\right]$. Only the first control move or control law is implemented and a new state measurement is taken. The nonlinear optimal control problem is then recalculated for the new time interval $\left[t_{k+1}, t_{k+1}+T\right]$, which leads to receding horizon control [11].

The nonlinear optimal control problem is to find a control profile $u(\cdot)$ such that it minimizes some scalar performance index

$$
\begin{aligned}
& \min _{x, u} \quad \phi_{c}(x, u) \\
& \text { s.t. } \quad \dot{x}(t)=f_{c}(x(t), u(t), \tilde{p}) \\
& \theta_{c}(x, u) \leq 0 \\
& t_{1} \triangleq 0, x_{1} \triangleq x\left(t_{1}\right) \\
& t_{f} \triangleq T, x_{f} \triangleq x\left(t_{f}\right), \psi\left(x_{f}\right)=0
\end{aligned}
$$

where $x: \mathbb{R} \rightarrow \mathbb{R}^{n_{x}}$ is the state trajectory, $u: \mathbb{R} \rightarrow \mathbb{R}^{n_{u}}$ is the control trajectory, $x(t) \in \mathbb{R}^{n_{x}}$ is the state vector, $\dot{x}(t) \in \mathbb{R}^{n_{x}}$ is the state sensitivities to time, $u(t) \in \mathbb{R}^{n_{u}}$ is the control vector, $x_{f} \in \mathbb{R}^{n_{x}}$ is the terminal state vector, $(x, u) \mapsto \phi_{c}(x, u)$ is 
the scalar performance function, $(x, u) \mapsto \theta_{c}(x, u)$ is the inequality constraints function, $\psi: \mathbb{R}^{n_{x}} \rightarrow \mathbb{R}$ is the terminal constraint function, $\tilde{p} \in \mathbb{R}^{n_{p}}$ is the nominal parameter vector, and $f_{c}: \mathbb{R}^{n_{x}} \times \mathbb{R}^{n_{u}} \times \mathbb{R}^{n_{p}} \rightarrow \mathbb{R}^{n_{x}}$ is the ordinary differential equation describing the dynamics of the plant. The plant dynamics are time invariant and each optimal control problem can therefore be solved from time $t_{1}=0$ without affecting the result. The initial state value $x_{1} \in \mathbb{R}^{n_{x}}$ is the currently measured state of the system. The final state $x_{f} \in \mathbb{R}^{n_{x}}$ will be a fixed value based on the setpoint for the current iteration of the optimization problem, because the terminal constraints are defined as equality constraints (38). The final state value $x_{f}$ may vary from iteration to iteration if setpoint changes are made. The final time $t_{f}$ of the optimization problem is fixed for this implementation.

For the sequel the ordered pair $(a, b) \triangleq\left[\begin{array}{cc}a^{T} & b^{T}\end{array}\right]^{T}$ is defined as a column vector.

Plant models, such as the mill circuit model described above, always differ from the real system owing to incomplete modelling, parameter uncertainty and unmodelled disturbances. The NMPC developed earlier in [12] will be extended to explicitly deal with model parameter uncertainty. Consider an uncertain parameter vector $p \in \mathbb{R}^{n_{p}}$ and nominal parameter vector $\tilde{p} \in \mathbb{R}^{n_{p}}$, which are assumed to be restricted to a generalized ball $\mathbb{P}=\left\{p \in \mathbb{R}^{n_{p}} \mid\|p-\tilde{p}\| \leq 1\right\}$ defined by using a suitable norm $\|\cdot\|$ in $\mathbb{R}^{n_{p}}[13]$.

A suitable uncertainty description for the parameters is box uncertainty where the upper $p_{u}$ and lower $p_{l}$ bounds on the parameters $p$ are known

$$
\begin{aligned}
\mathbb{P}_{\text {box }} & \triangleq\left\{p \in \mathbb{R}^{n_{p}} \mid p_{l} \leq p \leq p_{u}\right\} \\
& =\left\{p \in \mathbb{R}^{n_{p}} \mid\left\|\operatorname{diag}\left(\frac{p_{u}-p_{l}}{2}\right)^{-1}\left(p-\frac{p_{l}+p_{u}}{2}\right)\right\|_{\infty} \leq 1\right\}
\end{aligned}
$$

where the center of the box is defined as $\bar{p} \triangleq\left(p_{l}+p_{u}\right) / 2 \in$ $\mathbb{R}^{n_{p}}$. In general, the center of the box $\bar{p}$ and the nominal parameter vector $\tilde{p}$ do not have to be the same point $(\tilde{p} \neq \bar{p})$.

The nonlinear optimal control problem, consisting of a system with continuous dynamics, needs to be discretized in order to be cast in terms of a nonlinear parameter optimization problem, using the direct multiple shooting method [14]. This is accomplished by dividing the prediction horizon $[0, T]$ into $N$ discrete time intervals called nodes $t_{1} \triangleq 0<t_{2}<t_{3}<\cdots<t_{k}<\cdots<t_{N-1}<t_{N} \triangleq T$, where the sampling time is defined as $\tau_{s} \triangleq t_{k+1}-t_{k}$.

The functions of time $x(\cdot)$ and $u(\cdot)$ are replaced by their values at the nodes $x_{k} \in \mathbb{R}^{n_{x}}$ and $u_{k} \in \mathbb{R}^{n_{u}}$ for $k=1, \ldots, N$ and some form of interpolation between nodes. The resulting nonlinear controlled discrete-time system is $x_{k+1} \triangleq f_{k}\left(x_{k}, u_{k}, \tilde{p}\right), k=1,2, \ldots, N-1$. The nonlinear optimal control problem can now be cast into the following nonlinear parameter optimization problem

$$
\begin{array}{ll}
\min _{\mathbf{s}, \mathbf{q}} & \phi(\mathbf{s}, \mathbf{q}) \\
\text { s.t. } & g(\mathbf{s}, \mathbf{q}, \tilde{\mathbf{p}})=0 \\
\theta_{i, j}\left(s_{j}, q_{j}\right) \leq 0,{ }^{i}=1, \ldots, n_{c}, \\
j=1, \ldots, N-1, \\
\theta_{N}\left(s_{N}\right)=0
\end{array}
$$

where $\phi: \mathbb{R}^{N \cdot n_{x}} \times \mathbb{R}^{(N-1) \cdot n_{u}} \rightarrow \mathbb{R}$ is the performance function to be optimized, $g: \mathbb{R}^{N \cdot n_{x}} \times \mathbb{R}^{(N-1) \cdot n_{u}} \times \mathbb{R}^{(N-1) \cdot n_{p}} \rightarrow$ $\mathbb{R}^{N \cdot n_{x}}$ is the equality constraint function that describes the discrete time system dynamics, $\theta_{i, j}: \mathbb{R}^{n_{x}} \times \mathbb{R}^{n_{u}} \rightarrow \mathbb{R}, \quad i=$ $1, \ldots, n_{c}, j=1, \ldots, N-1$ are the inequality constraint functions, $\theta_{N}: \mathbb{R}^{n_{x}} \rightarrow \mathbb{R}$ is the terminal constraint function, $s_{i} \in \mathbb{R}^{n_{x}}, i=1, \ldots, N$ are the estimated state parameters, $q_{i} \in \mathbb{R}^{n_{u}}, i=1, \ldots, N-1$ are the control parameters, $\tilde{\mathbf{p}} \triangleq(\tilde{p}, \ldots, \tilde{p}) \in \mathbb{R}^{(N-1) n_{p}}$ is the sequence of nominal model parameters, $\mathbf{s} \triangleq\left(s_{1}, \ldots, s_{N}\right)$ is the state sequence and $\mathbf{q} \triangleq\left(q_{1}, \ldots, q_{N-1}\right)$ is the control sequence to be optimized in the nonlinear optimization problem [14].

The scalar performance function is defined as

$$
\phi(\mathbf{s}, \mathbf{q}) \triangleq \sum_{i=1}^{N-1} L_{i}\left(s_{i}, q_{i}\right)+E\left(s_{N}\right)
$$

where the scalar interval performance indexes are defined as

$$
L_{i}\left(s_{i}, q_{i}\right) \triangleq h\left(s_{i}, q_{i}\right)^{T} Q h\left(s_{i}, q_{i}\right)+\Delta q_{i}^{T} R \Delta q_{i}
$$

where $Q$ and $R$ represent the weighting matrices on the outputs and controls respectively, $h: \mathbb{R}^{n_{x}} \times \mathbb{R}^{n_{u}} \rightarrow \mathbb{R}^{n_{y}}$ is the function that maps the current state and control vector to the output vector using nominal model parameters and $\Delta q_{i} \triangleq q_{i}-q_{i-1}$. The output vector consists of PSE, LOAD, SLEV, Rheology factor $(\varphi)$, THROUGHPUT, and mill motor power draw $\left(P_{\text {mill }}\right)$. The terminal performance index is defined as

$$
E\left(s_{N}\right) \triangleq h\left(s_{N}, q_{N-1}\right)^{T} P h\left(s_{N}, q_{N-1}\right)
$$

where $P$ is the terminal cost weighting matrix. The equality constraint function describing the discrete time system dynamics is defined as

$$
g(\mathbf{s}, \mathbf{q}, \mathbf{p}) \triangleq\left\{\begin{array}{l}
x_{k}-s_{1}, \\
f_{1}\left(s_{1}, q_{1}, p_{1}\right)-s_{2}, \\
\vdots \\
f_{N-1}\left(s_{N-1}, q_{N-1}, p_{N-1}\right)-s_{N} .
\end{array}\right.
$$

To add uncertainty into an optimization problem, a min-max optimization can be done [13], [15]. The worst-case values for the cost $\phi(\mathbf{s}, \mathbf{q})$ is defined as $\psi(\mathbf{q}) \triangleq$ $\max _{\mathbf{s}, \mathbf{p}} \phi(\mathbf{s}, \mathbf{q})$ s.t. $g(\mathbf{s}, \mathbf{q}, \mathbf{p})=0$ and the worst-case values for the constraint functions $\theta_{i, j}\left(s_{j}, q_{j}\right)$ are defined as $\omega_{i, j}\left(q_{j}\right) \triangleq \max _{\mathbf{s}, \mathbf{p}} \theta_{i, j}\left(s_{j}, q_{j}\right)$ s.t. $g(\mathbf{s}, \mathbf{q}, \mathbf{p})=0$, where $p_{i} \in \mathbb{P}_{\text {box }}, i=1, \ldots, N-1$ is defined as the unknown time varying model parameters and $\mathbf{p} \triangleq\left(p_{1}, \ldots, p_{N-1}\right) \in \mathbb{P}_{\text {box }}^{(N-1)}$ is defined as the sequence of time varying model parameters. The worst-case cost and constraint functions are calculated by maximizing the cost function and constraint functions with regard to the model parameter sequence $\mathbf{p} \in \mathbb{P}_{\text {box }}^{(N-1)}$ and state values $\mathbf{s} \in \mathbb{R}^{\left(N \cdot n_{x}\right)}$. The worst-case cost function $\psi(\mathbf{q})$ is then minimized by choosing the control moves $\mathbf{q} \triangleq\left(q_{0}, q_{1}, \ldots, q_{N-1}\right) \in \mathbb{R}^{\left((N-1) \cdot n_{u}\right)}$ subject to the worst-case constraints $\omega_{i, j}, i=1, \ldots, n_{c}, j=1, \ldots, N-1$.

This min-max optimization problem is difficult to solve for general nonlinear systems. The optimization problem can however be simplified by approximating the worst-case calculations for the cost $\tilde{\psi}(\mathbf{s}, \mathbf{q})$ and the constraints 
$\tilde{\omega}_{i, j}(\mathbf{s}, \mathbf{q}), \quad i=1, \ldots, n_{c}, \quad j=1, \ldots, N-1$. The approximation of the worst-case cost $\tilde{\psi}(\mathbf{s}, \mathbf{q})$ and constraints $\tilde{\omega}_{i, j}(\mathbf{s}, \mathbf{q})$ can be done through linearization of the system dynamics $g(\mathbf{s}, \mathbf{q}, \mathbf{p})=0$, the cost $\phi(\mathbf{s}, \mathbf{q})$, and constraint $\theta_{i, j}\left(s_{j}, q_{j}\right)$ functions.

The approximation of the worst-case $\operatorname{cost} \psi(\mathbf{s}, \mathbf{q})$ by $\tilde{\psi}(\mathbf{s}, \mathbf{q})$, is defined by a convex optimization problem

$$
\begin{aligned}
& \max _{\Delta \mathbf{s}, \Delta \mathbf{p}} \phi(\mathbf{s}, \mathbf{q})+\frac{\partial \phi(\mathbf{s}, \mathbf{q})}{\partial \mathbf{s}} \Delta \mathbf{s} \\
& \text { s.t. } \frac{\partial g(\mathbf{s}, \mathbf{q}, \overline{\mathbf{p}})}{\partial \mathbf{s}} \Delta \mathbf{s}+\frac{\partial g(\mathbf{s}, \mathbf{q}, \overline{\mathbf{p}})}{\partial \mathbf{p}} \Delta \mathbf{p}=0, \\
& \left\|\Delta p_{l}\right\| \leq 1, l=1, \ldots, N-1
\end{aligned}
$$

and the approximation of the worst-case constraints $\omega_{i, j}(\mathbf{s}, \mathbf{q})$ by $\tilde{\omega}_{i, j}(\mathbf{s}, \mathbf{q})$ are defined as

$$
\begin{aligned}
& \max _{\Delta \mathbf{s}, \Delta \mathbf{p}} \theta_{i, j}\left(s_{j}, q_{j}\right)+\frac{\partial \theta_{i, j}\left(s_{j}, q_{j}\right)}{\partial \mathbf{s}} \Delta \mathbf{s} \\
& \text { s.t. } \frac{\partial g(\mathbf{s}, \mathbf{q}, \overline{\mathbf{p}})}{\partial \mathbf{s}} \Delta \mathbf{s}+\frac{\partial g(\mathbf{s}, \mathbf{q}, \overline{\mathbf{p}})}{\partial \mathbf{p}} \Delta \mathbf{p}=0, \\
& \left\|\Delta p_{l}\right\| \leq 1, l=1, \ldots, N-1
\end{aligned}
$$

where $\Delta \mathbf{s} \in \mathbb{R}^{\left(N \cdot n_{x}\right)}, \overline{\mathbf{p}} \triangleq(\bar{p}, \ldots, \bar{p}) \in \mathbb{R}^{(N-1) \cdot n_{p}}$ is a sequence of parameters at the center of the box, $\Delta p_{l} \triangleq p_{l}-\bar{p} \in$ $\mathbb{R}^{n_{p}}$ is the deviation of the model parameters from the center of the box and $\Delta \mathbf{p} \triangleq\left(\Delta p_{1}, \ldots, \Delta p_{N-1}\right) \in \mathbb{R}^{(N-1) \cdot n_{p}}$ is defined as the sequence of model parameter deviations. The approximate min-max problem

$$
\begin{array}{ll}
\min _{\mathbf{s}, \mathbf{q}} & \tilde{\psi}(\mathbf{s}, \mathbf{q}) \\
\text { s.t. } & \tilde{\omega}_{i, j}(\mathbf{s}, \mathbf{q}) \leq 0, \begin{array}{l}
i=1, \ldots, n_{c} \\
j=1, \ldots, N-1 .
\end{array} \\
g(\mathbf{s}, \mathbf{q}, \overline{\mathbf{p}})=0
\end{array}
$$

can be solved efficiently by casting it into a form that preserves the sparsity of the problem as well as smooth objective and constraint functions [13].

\section{Simulation And Results}

A simulation study is shown where the RNMPC of Section III is applied to the ROM milling model presented in Section II-B.

In this simulation scenario, the "actual" plant differs from the nominal model. The prediction horizon, sampling time, number of nodes and simulation time is summarised in Table IV. The milling circuit model contains large parameter uncertainties; this is especially true of the parameters related to the composition of the feed-ore and the hardness of the ore, which has an impact on the energy needed to grind a ton of ore. The parameter variations used in the simulation study are shown in Table III. The parameter vector changes every $200 \mathrm{~s}$, to allow the parameter disturbances to sufficiently impact the simulation. The parameters follow a uniform distribution to produce large changes in the parameter values in order to properly demonstrate the disturbance rejection capabilities of the controller.

The milling circuit is simulated at the operating point as described by the "OP" column in Table II. The constraints of the milling circuit are described by the "Min" and "Max"
TABLE IV

SIMULATION SUMMARY

\begin{tabular}{lclc}
\hline Variable & Value & Variable & Value \\
\hline Prediction Horizon $(T)$ & 60 seconds & Nodes $(N)$ & 6 \\
Sampling Time $\left(\tau_{s}\right)$ & 10 seconds & Simulation time & 260 minutes \\
\hline
\end{tabular}

columns in Table II. Metric ton is used throughout this brief. The weighting of the variables in $Q$ and $R$ of (40) is described by the "W" column in Table II and chosen based on the performance criteria of Section II-A. Further, $P=Q$ with no terminal constraints $\left(\theta_{N}\left(s_{N}\right) \in \mathbb{R}^{N_{x}}\right)$. The inputs are normalised according to their maximum range and outputs are normalized according to their setpoints in the objective function.

Feed ore hardness and composition changes are major disturbances that milling circuit controllers have to contend with, especially when the feed ore is switched between feeds that originate from different stockpiles. A feed ore hardness increase is simulated by increasing the power needed to produce a ton of fines $\left(\phi_{f}\right)$ by $50 \%$ at time $10 \mathrm{~min}$. A feed ore composition change is simulated by increasing the fraction of the feed consisting of rock $\left(\alpha_{r}\right)$ by $50 \%$ at time $100 \mathrm{~min}$. These disturbances are very large but not uncommon in practice.

PSE is controlled through changing the cut of the cyclone. The cut of the cyclone is changed through the CFF [see Fig. 2(b)] and the cyclone feed density (CFD). The CFD [see Fig. 2(b)] can be changed by changing the mill discharge density through the ratio of MIW to MFS [see Fig. 2(b)] and, more importantly, by changing the sump slurry density through SFW [see Fig. 2(b)]. CFD should be constrained by the controller to ensure efficient cyclone operation. The controller therefore has three degrees of freedom with which to control the PSE. The SLEV [see Fig. 2(a)] is allowed to vary freely between its constraints (showing large variations), allowing the controller to control the density of the slurry in the sump.

PSE and LOAD are maintained at their desired setpoints of $80 \%$ and $45 \%$ respectively under RNMPC [see Fig. 2(a)] regardless of the active disturbances.

Fig. 2(b) shows a slight drop in average MFS due to the increased hardness of the ore. The variations in MFS can be attributed to the varying ore hardness that affects the residence time of the ore inside the mill. The large variations in SFW is to manipulate the SLEV in such a way as to minimise the sump slurry density.

Fig. 2(a) further shows the product THROUGHPUT, Rheology of the slurry inside the mill and the power draw of the mill motor. MFS represents the throughput of new feed ore to the mill, while THROUGHPUT represents the product throughput that is sent down stream for further processing. At steady state, these two values should be the same. The throughput settles at a lower value, because the feed ore hardness was increased, thus deviating from the nominal operating conditions. The controller reduces THROUGHPUT in order to maintain PSE at setpoint, which is weighted as being more important. If, however, THROUGHPUT is weighted as more important, the THROUGHPUT will remain closer the operating point, while PSE will decline.

The rheology factor is a function of the water and solids inside the mill as shown in (6). The RNMPC manipulates MIW 

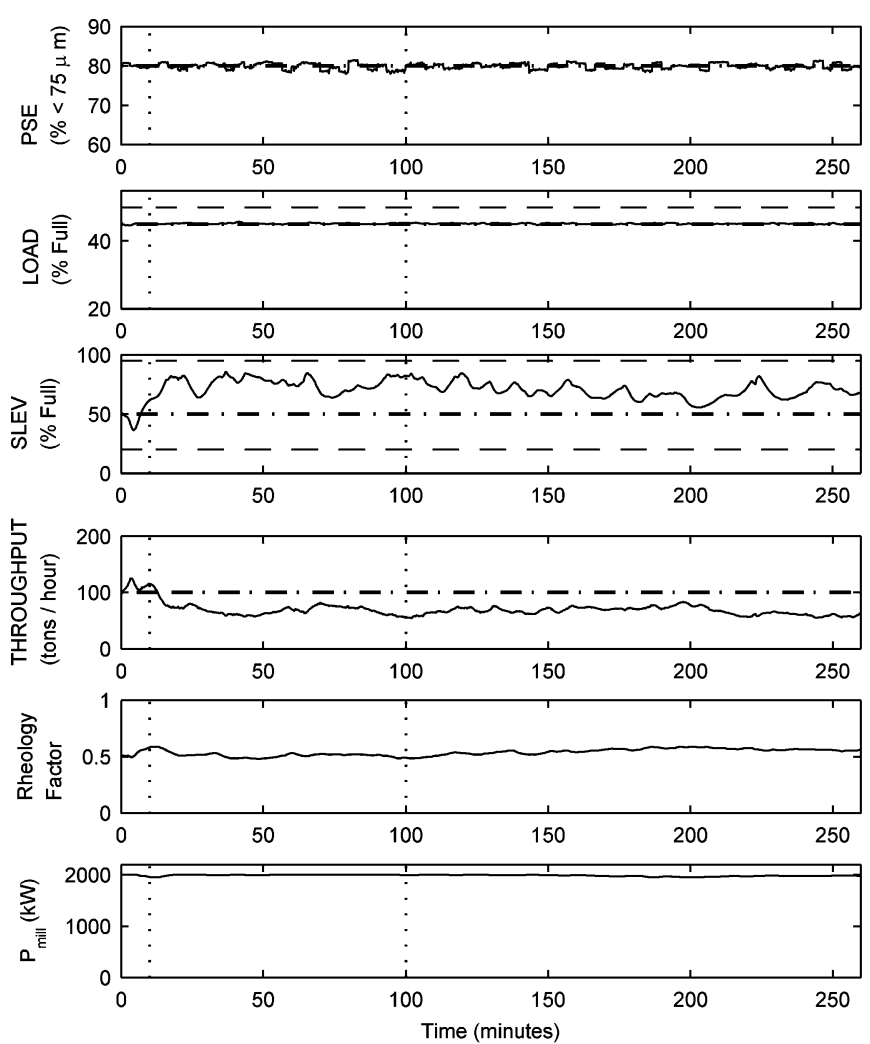

(a) PSE, LOAD, SLEV and THROUGHPUT are CVs. Rheology Factor and $P_{\text {mill }}$ are important variables.
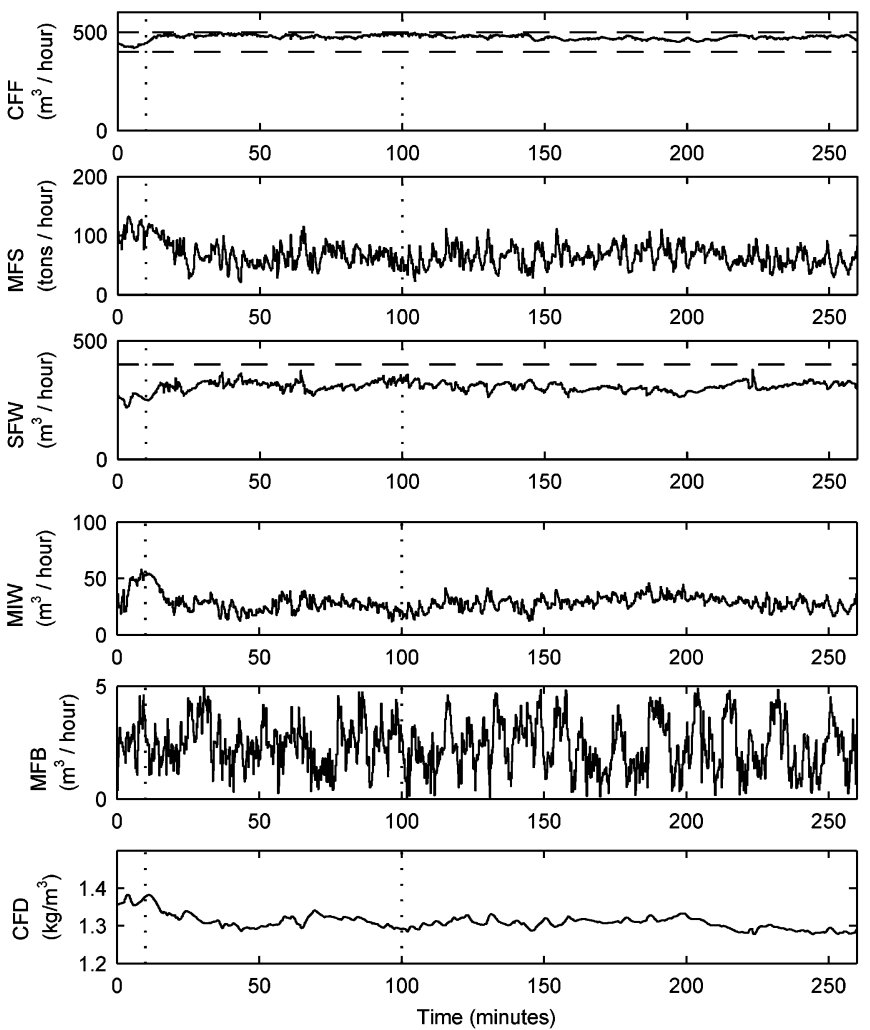

(b) CFF, MFS, SFW, MIW and MFB are MVs. CFD is an important variable.

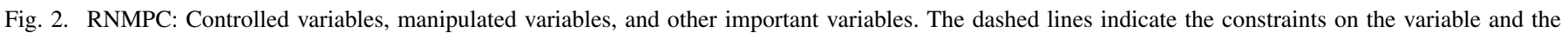
vertical dotted lines indicate the start of the disturbance events. The dashed-dotted line indicates the setpoint.

and MFS to maximise throughput by maintaining optimum breakage conditions inside the mill, which is obtained when the rheology factor is at the optimum value of 0.51 . The controller compensates for the feed ore hardness disturbance by increasing MIW relative to MFS in order to reduce the mill discharge density and together with an increase in SFW reduces CFD to maintain PSE at setpoint. The increase of MIW relative to MFS leads to an increase in the rheology factor and as a result a drop in mill power. The RNMPC increases MFB [see Fig. 2(b)] to compensate for the higher rheology factor in order to maintain proper breakage conditions inside the mill.

Table II shows that there are degrees-of-freedom available that can, e.g., be used to minimize the power consumption of the mill by giving it a low setpoint and maximize throughput by giving it a high setpoint. These are however competing objectives, as discussed in Section II-A, and hence care should be taken when assigning controller weights to these variables.

\section{IMPLEMENTATION ISSUES}

The RNMPC was implemented using open-source optimization software IPOPT [16] and open-source automatic differentiation software CppAD [17]. The simulation executed with an average time of about $26 \mathrm{~s}$ and a maximum time of $123 \mathrm{~s}$ per iteration on a Dell PowerEdge 1955 blade with Intel Xeon 5140 (Dual-Core) $2.33 \mathrm{GHz}$ processor, $2 \mathrm{~GB}$ RAM, and $1333 \mathrm{MHz}$ FSB. This platform is typically faster than the implementation platforms available on most mineral processing plants.
The current RNMPC implementation is not feasible for practical implementation, because the maximum and average calculation times are much longer than the recommended sampling time. Process time constants for the dynamics that relate the MFS to LOAD and PSE are in the order of $30 \mathrm{~min}$, whereas the time constants relating CFF and SFW to PSE are in the order of one or $2 \mathrm{~min}$. Hence a sampling time of $10 \mathrm{~s}$ is recommended in [1]. An additional motivation for this choice of sampling time is that during normal operation the sump volume is about $5 \mathrm{~m}^{3}$ and the flow rates of CFF and SFW range from 400 to $500 \mathrm{~m}^{3} / \mathrm{h}$ and 0 to $400 \mathrm{~m}^{3} / \mathrm{h}$, respectively. If for example the difference between CFF and SFW is $300 \mathrm{~m}^{3} / \mathrm{h}$, the sump will run dry or overflow within about $1 \mathrm{~min}$. There are various factors that influence the calculation time. Increasing the prediction horizon significantly increases the calculation time because of an increase in decision variables and total integration time. Tuning the controller will include the selection of the prediction horizon for stability and performance, while maintaining a reasonable calculation time. The optimization problem could potentially also be reformulated to reduce the number of decision variables and/or make the problem more suitable for implementation on a multiprocessing platform. The computation time can also be reduced by using less nodes without affecting the prediction horizon $T$, leading to an effective shorter control horizon. The control algorithm is hampered mainly by a large number of slack variables for implementing robustness and the Hessian calculations. With the continuous increase in computing power, this should become less of an issue in the foreseeable future. 
The simulation further assumed full-state feedback which is not available on real plants. Typically the controlled variables PSE, SLEV, LOAD, and the cyclone feed or sump density would be measured online [2] from which an observer would need infer the model states.

\section{CONCLUSION}

Advanced control such as MPC has not been as readily adopted by the mineral processing industry as compared to, for example, the petrochemical industry [2]. This brief investigated the feasibility of applying RNMPC to a ROM ore milling circuit and the conditions under which such a controller might be worthwhile implementing.

A comprehensive modularized ROM ore milling circuit model was described and cast into an RNMPC framework. The results of a practically motivated simulation show that an RNMPC controller can successfully control important milling circuit variables in the face of large disturbances that are not uncommon in practice.

Some implementation issues were also discussed. For example, it was found that the RNMPC calculation time is currently too long for commonly used implementation platforms. This should however not be a problem for long as computing power is increasing all the time.

The adoption of advanced control by the mineral processing industry will probably be determined by the tradeoff between the added complexity of implementing and maintaining an advanced controller such as RNMPC, and the benefits that can be derived from such an implementation. Results given in this brief suggest that if a milling circuit regularly experiences large feed ore hardness and composition changes, when for example the feed ore is switched between feeds that originate from different stockpiles, RNMPC might well warrant a closer look.

\section{ACKNOWLEDGMENT}

The authors would like to thank Dr. D. Hulbert of Mintek for the nonlinear milling circuit model and for the discussions on the modelling and control of milling circuits.

\section{REFERENCES}

[1] I. K. Craig and I. M. MacLeod, "Specification framework for robust control of a run-of-mine ore milling circuit," Control Eng. Practice, vol. 3, no. 5, pp. 621-630, 1995.

[2] D. Wei and I. K. Craig, "Grinding mill circuits-A survey of control and economic concerns," Int. J. Mineral Process., vol. 90, no. 1-4, pp. 56-66, 2009.

[3] M. Ramasamy, S. S. Narayanan, and C. D. P. Rao, "Control of ball mill grinding circuit using model predictive control scheme," J. Process Control, vol. 15, no. 3, pp. 273-283, 2005.

[4] R. K. Rajamani and J. A. Herbst, "Optimal control of a ball mill grinding circuit. I. Grinding circuit modeling and dynamic simulation," Chem. Eng. Sci., vol. 46, no. 3, pp. 861-870, 1991.

[5] P. Mhaskar and A. B. Kennedy, "Robust model predictive control of nonlinear process systems: Handling rate constraints," Chem. Eng. Sci., vol. 63, no. 2, pp. 366-375, 2008.

[6] M. Lazar, D. M. de la Pena, W. P. M. H. Heemels, and T. Alamo, "On input-to-state stability of min-max nonlinear model predictive control," Syst. Control Lett., vol. 57, no. 1, pp. 39-48, 2008

[7] G. G. Stanley, "The extractive metallurgy of gold in South Africa," South African Inst. Mining Metallurgy, Johannesburg, 1987, vol. 1.

[8] D. G. Hulbert, "The state of the art in the control of milling circuits," presented at the 6th IFAC Symp. Autom. Mining, Mineral Metal Process., Buenos Aires, Argentina, 1989.

[9] F. N. Shi and T. J. Napier-Munn, "Effects of slurry rheology on industrial grinding performance," Int. J. Mineral Process., vol. 65, no. 3-4, pp. 125-140, 2002.

[10] K. Nageswararao, D. M. Wiseman, and T. J. Napier-Munn, “Two empirical hydrocyclone models revisited," Minerals Eng., vol. 17, no. 5, pp. 671-687, 2004

[11] D. Q. Mayne, J. B. Rawlings, C. V. Rao, and P. O. M. Scokaert, "Constrained model predictive control: Stability and optimality," Automatica, vol. 36, pp. 789-814, 2000.

[12] L. C. Coetzee, I. K. Craig, and E. C. Kerrigan, "Nonlinear model predictive control of a run-of-mine ore milling circuit," presented at the 17th IFAC World Congr., Seoul, Korea, Jul. 2008.

[13] M. Diehl, H. G. Bock, and E. Kostina, "An approximation technique for robust nonlinear optimization," Math. Program.: Series A and B, vol. 107, no. 1, pp. 213-230, 2006.

[14] M. Diehl, H. G. Bock, and J. P. Schloder, "A real-time iteration scheme for nonlinear optimization in optimal feedback control," SIAM J. Control Optimization, vol. 43, no. 5, pp. 1714-1736, 2005.

[15] D. L. Ma and R. D. Braatz, "Worst-case analysis of finite-time control policies," IEEE Trans. Control Syst. Technol., vol. 9, no. 5, pp. 766-774, Sep. 2001.

[16] Y. Kawajir, C. Laird, and A. Wachter, "Introduction to Ipopt: A tutorial for downloading, installing, and using Ipopt," Carnegie Mellon Univ., Pittsburgh, PA, 2006. [Online]. Available: https://projects.coin-or.org/ Ipopt, 799

[17] R. Lougee-Heimer, "The common optimization interface for operations research," IBM J. Res. Developm., vol. 47, no. 1, pp. 57-66, Jan. 2003. 